\title{
Fogel, Jean-François \& Patino, Bruno (2005) Une Presse sans Gutenberg, Paris: Grasset
}

Luís António Santos"

“A Internet não é apenas mais um suporte; é o fim do Jornalismo tal como existiu até aqui. (...) A Imprensa não abriu um novo capítulo da sua História, mas antes iniciou uma outra História, sob o regime da Internet” (p. 16). É em expressões desta densidade dramática mas também desta clareza que Fogel e Patino ancoram a sua argumentação num livro que se inscreve com facilidade nas propostas que, perante o desafio do digital, percebem um espaço de sobrevivência para o Jornalismo.

A imagem do jornalismo, tal qual ela nos é apresentada, por exemplo, no filme de Richard Brooks, Deadline USA (1952) - em que o editor de um jornal ameaçado de extinção (Humphrey Bogart no papel de Ed Hutchenson) insiste em expor as actividades criminosas de um 'intocável' e lhe diz: "Enquanto existir um só jornal para imprimir a verdade, tu és um homem acabado" antes mesmo de dar instruções para fazer andar a rotativa - direccionava-nos para um universo em que a Imprensa existia imune à força e, às vezes, ao próprio Direito. Seria uma Imprensa depositária de uma ética da verdade, que se exprimia por ritmos que só obedeciam às regras do dia solar.

Nesse sentido, defendem os autores, a perspectiva de uma imprensa em linha, disponível a todo o instante, aporta "uma perturbação quasi cósmica a ponto de se poder pôr em causa a existência dos média tradicionais” (p. 217).

Poder-se-á eventualmente dizer que o recurso a um exemplo romantizado - e, naturalmente, distante da realidade do jornalismo tal qual ela é - nos revela tons de fragilidade na argumentação. Perde-se, porventura, alguma da segurança necessária ao tratamento de um tema como este e pode ainda perder-se alguma da espessura desejada. De maneira alguma, porém, devem estas limitações (ou nem isso) afastar-nos do essencial sob pena de cometermos grave injustiça aos autores e aos seus intentos.

O livro dá-nos testemunho de um momento a que poucas gerações de jornalistas tiveram a rara oportunidade de assistir, o da construção de um novo território para a profissão e para o seu exercício, com todas as vantagens e restrições que forçosamente sempre encerram. Este trabalho é, portanto, um documento engajado, cuja vitalidade e riqueza advêm fundamentalmente da experiência adquirida na 'tarimba', no contacto directo com um projecto de implementação de jornalismo digital, traçando-nos retratos vivos não apenas da fluidez inerente, mas também da emergência (ou sinais disso) de um processo de criação partilhada do enquadramento necessário à adaptação do jornalismo.

Jean-François Fogel, jornalista, consultor e escritor, e Bruno Patino, director da publicação Télérama, presidente do Monde Interactif e editor do monde.fr, estiveram

${ }^{*}$ Professor de Jornalismo na Universidade do Minho e investigador do Centro de Estudos de Comunicação e Sociedade da mesma Universidade (lsantos@ics.uminho.pt). 
ambos envolvidos, a partir de 2000, no dinâmico processo de criação e adaptação do Le Monde à existência na rede e o livro apresenta-nos esse ambiente de muitas dúvidas e algumas certezas incertas em que um saber profissional enfrenta, em permanência, a necessidade de se rever.

O trabalho apresenta-se em oito partes, sendo que a primeira se intitula "o novo regime do jornalismo" e a última nos fala do "fim dos meios de massa". Pelo caminho, contam-se espaços dedicados ao "navegador rei", à "atracção da rede", à "escrita e palavras" e à "centrifugadora digital". Na percepção dos autores, este novo jornalismo não é uma transposição (ainda que com ajustes) dos processos de produção e formatação do jornalismo já existentes para um outro ambiente e isso exprime-se de forma eloquente, logo na primeira parte, quando nos é apresentada, como metáfora, a história do camionista que não transportava nada (durante anos, atravessou um posto fronteiriço em ambos os sentidos e sempre que era parado para inspecção não tinha carga nenhuma; um dia, um dos inspectores disse-lhe: esta é a minha última noite de trabalho e por isso, sob compromisso de que não o vou punir, gostava que me tirasse uma dúvida que tenho há anos - diga-me, afinal, qual é o seu negócio? O que trafica? Divisas? Ouro? Passageiros clandestinos? O homem respondeu com uma só palavra: 'camiões'). Para Fogel e Patino a parcialidade do olhar - que nos leva a centrar atenções na 'carga' - é um "défice de reconhecimento" que o jornalismo em linha ainda carrega e que pode levar-nos a ignorar (ou a desvalorizar) o que lhe dá especificidade.

Os autores não duvidam de que nasceu já na Internet um novo jornalismo, com identidade e linguagem autónomas (p. 17), que de longe ultrapassa a soma aritmética dos excertos que extraiu aos universos da escrita e do audiovisual: "Seria um erro acreditar que a Internet se contenta com o despojar cada meio daquilo que possui de único - o monopólio do texto à escrita e o sincronismo da recepção ao audiovisual - em benefício do seu próprio fluxo, múltiplo, reactivo, interactivo. O regime da Internet é bem pior: corrói a concorrência entre as formas de jornalismo (...) e varre as definições estreitas: a rádio anuncia a novidade, a televisão mostra-a e o jornal enquadra-a. Num site todos os conteúdos desfilam na mesma rede com um só sinal: disponível em linha. No ecrã, as especificidades de cada tipo de jornalismo tornam-se simples variações duma só experiência, o jornalismo difundido pela Internet" (p. 28).

Apesar dos "fervores analógicos" que esta mudança acarreta, o Jornalismo precisa de pensar nela como uma oportunidade: "O jornalismo, independentemente do meio, vai ter que se construir ou reconstruir em torno de realidades que se tornaram incontornáveis: o primado da Internet, a obrigatoriedade de as empresas organizarem a sua presença na rede e, por fim, a coexistência de dois mundos, que os jornalistas precisam de saber cobrir. Aqui está o novo regime do Jornalismo nos tempos do digital (...) O exílio não será sequer uma opção viável para quem quer que seja” (p. 35).

Jean-François Fogel e Bruno Patino dizem-nos que se "respira um outro ar" no jornalismo digital e este livro é testemunho disso mesmo. Não tanto do facto em si - de avaliação mais difícil do que nos fazem crer - mas sobretudo do seu empenho em que assim possa ser. E, nesse sentido, o trabalho de ambos é de leitura essencial para quem se interessa pelos caminhos do jornalismo em face do desafio do digital. 